\title{
Determinants of Postpartum Contraception Use Among Teenage Mothers in Eastern Uganda: A Cross-Sectional Study
}

This article was published in the following Dove Press journal: Open Access Journal of Contraception

\author{
Doreen L Muyama' \\ Milton W Musaba $\mathbb{D D}^{2}$ \\ Ronald Opito $\mathbb{D D}^{3}$ \\ David J Soita' \\ Julius $\mathrm{N}$ Wandabwa ${ }^{2}$ \\ Dinah Amongin ${ }^{4}$ \\ 'Department of Public and Community \\ Health, Faculty of Health Sciences, \\ Busitema University, Mbale, Uganda; \\ ${ }^{2}$ Department of Obstetrics and \\ Gynecology, Faculty of Health Sciences, \\ Busitema University, Mbale, Uganda; \\ ${ }^{3}$ Department of Programs, Population \\ Services International, Kampala, Uganda; \\ ${ }^{4}$ Department of Health Policy Planning \\ and Management, Makerere University \\ School of Public Health, Kampala, Uganda
}

Introduction: In Uganda, the proportion of women having another live birth before age 20 years (repeat adolescent birth) has not declined in 30 years. More women want to delay the next birth. We determined the prevalence and factors associated with postpartum contraceptive use among teenage mothers in Mbale City.

Patients and Methods: We conducted a cross-sectional study in all the six governmentsupported health facilities within Mbale City. Over a period of 3 months, 511 teenage mothers in the postpartum period were consecutively enrolled by midwives/nurses. Data were collected using a pretested interviewer-administered questionnaire. We used logistic regression in STATA version 14, to determine the association between various sociodemographic characteristics and utilization of contraception. We set the level of significance at $5 \%$ and report odds ratios and the corresponding $95 \%$ confidence intervals.

Results: Most of the respondents $-314 / 511$ [61.5\%, 95\% CI= 57.1-65.6\%] - were using contraceptives. More than three-fourth (238/314) of the respondents opted for short-term methods of contraception. In the adjusted analyses, intention to resume school [AOR 1.79 (1.16-2.74)], and utilization of maternal Child Heath services such as postnatal care services [AOR $0.40(0.25-0.63)$ ] were significantly associated with utilisation of postpartum contraception.

Conclusion: We found a high prevalence of postpartum contraceptives use - over 6 in 10 women - although they were using mainly short-term methods. Those with intentions of resuming schooling and utilised postnatal care services were most likely to use contraceptives. This is encouraging and calls for inquiry into why their use is higher than the national averages. Further, the results call for renewed efforts to maintain adolescent mothers in school.

Keywords: contraceptive use, postpartum, teenage mother, Uganda, determinants

\section{Introduction}

Adolescent pregnancy remains a major public health priority due to the associated negative health, social, and economic outcomes. ${ }^{1}$ Globally, more than 16 million adolescent pregnancies occur and almost all (95\%) are in the low- and middleincome countries in sub-Sahara Africa. ${ }^{2,3}$ In Uganda, $25 \%$ of adolescents (age 15-19 years), have begun childbearing and this proportion has plateaued at this rate in the last two decades. ${ }^{4}$ An analysis of the six Uganda demographic health surveys on time trends in and factors associated with repeat adolescent birth in Uganda found that following first birth at less than 18 years, the proportion of
Correspondence: Milton W Musaba Faculty of Health Sciences, Busitema University, Mbale, Uganda Tel +25670491379l

Email miltonmusaba@gmail.com 
Uganda adolescent women aged between 20 and 24 years who reported a repeat birth before 20 years of age is highabove $50 \%$ with no decline registered in the last 30 years. ${ }^{4}$ In addition to the latter, a study by Guttmacher institute in 2018 found that within 12 months of a first pregnancy, $37 \%$ had experienced a rapid repeat pregnancy within 12 months and $74 \%$ within 24 months. $^{5}$

The unmet need for family planning among teenagers in Uganda aged $15-19$ is $30.4 \%{ }^{6}$ This puts them at high risk of rapid repeat pregnancy which predisposes the girl and her offspring to a myriad of negative outcomes both in the short and long term. ${ }^{1}$ The negative health outcomes such as postpartum hemorrhage, anemia, and spontaneous abortion. In addition, there are social outcomes that include; rejection by family, discrimination in society. Socioeconomically, they face challenges such as premature cessation of schooling, lack of income to take care of themselves and the index child leading to malnutrition. ${ }^{1}$

The postpartum period is a key intervention point to prevent a repeat adolescent pregnancy and its associated sequalae. It presents a unique opportunity for counselling and initiation of postpartum contraception in the first 12 months after childbirth. ${ }^{7,8}$ According to the 2006 World Health Report, it was found that if couples could space their pregnancies by at least 24 months, up to $35 \%$ of the maternal deaths and $13 \%$ of the childhood mortalities could be averted. Similarly, $25 \%$ of under-five mortalities could be averted if birth intervals were at least 36 months. ${ }^{9,10}$ Among women of reproductive age (15-49) years in Uganda, use of modern family planning is associated with years of education, richest wealth status, Anglican religion and the age of the woman. While the use of postpartum family was associated with the number of surviving children, exposure to media, skilled birth attendance and early timing for postnatal care. ${ }^{11,12}$

Mbale City is inhabited by people of varying socioeconomic status. ${ }^{13}$ Rural-urban migration has increased the number of teenagers in urban and peri-urban areas. Adolescents in urban and peri-urban areas are very vulnerable because they are more prone to exploitation, poor access to health services and information with potentially high fertility rates which has contributed to the stagnating high number of teenage pregnancies. ${ }^{14}$ Therefore, knowing their postpartum contraceptive uptake is crucial because it will inform health-care providers and managers to design targeted interventions and programs to prevent rapid repeat pregnancies. Consequently, this will lead to improved health and economic status as well as general development to the study population. In response to this gap, we determined the prevalence of postpartum contraceptives use and its determinants among teenage mothers in an urban setting in Eastern Uganda.

\section{Patients and Methods Study Design}

This was a cross-sectional study conducted in all the six government-supported health facilities within Mbale city.

\section{Study Area}

Mbale City has a large urban and peri-urban population of varying socio-economic status comprised mainly youths. ${ }^{13}$ The city consists of three divisions; industrial, Northern, and Wanale divisions. ${ }^{13}$ It has five public health facilities served by one regional referral hospital. In total, these facilities serve a total population of 4 million from the surrounding 24 districts in the Elgon and Bukedi subregions. ${ }^{15}$

\section{Study Population}

We targeted all postpartum women that attend any of these six facilities to seek for maternal and child health care services during the study period. Using the registration details, the records assistants at the various health facilities identified potential participants and informed the research team members.

\section{Eligibility Criteria}

We included all teenage mothers who had given birth in the last 1 year from the day of the interview at any of the six health facilities, only those that were not residents of the city were excluded from the study.

\section{Sample Size and Sampling}

We used the formula for determining sample size for frequency (single proportion) in a population as described in Open Epi, Version 3, open source calculator. ${ }^{16} \mathrm{We}$ assumed that the percentage frequency of the outcome factor (contraception use) in the population (p) was 50\% since there were no published studies from this setting. We further assumed a design effect (DEFF) of 1, a power of $80 \%$ and $95 \%$ confidence level. After correcting for a nonresponse rate of $10 \%$, it was estimated that a sample size of 511 would be sufficient to determine the associated factors. Over a period of 3 months, the research assistants consecutively enrolled teenage mothers from the six health 
facilities on a daily basis until the estimated sample size was achieved. The research assistants were qualified midwives and nurses working within the same facility.

\section{Study Variables}

Our dependent variable was contraceptives use among teenage mothers, defined as the current or previous use of any modern contraceptive method after child birth up to 12 months postpartum.

The independent variables were factors associated with use of contraceptives within 12 months postpartum. We examined several socio-economic factors such as the level of education, partner influence, antenatal, and postnatal care attendance, perceived risk of getting pregnant, place of delivery, religion, on postpartum contraceptive use. We also collected information on the contraceptive methods used by teenagers in the postpartum period such as oral contraceptives, Injectables such as Depo-Provera, Sayana Press, Implanon, Jadelle and intrauterine devices (IUD). These factors were selected on the basis of previous study findings on predictors of contraceptive use among teens. ${ }^{17}$

\section{Data Collection}

Well-trained research assistants who were qualified midwives working within the same facilities used a pretested interviewer-administered questionnaire in the local dialects to obtain data. Data from each of the six health facilities were obtained from all eligible respondents who had brought their children for immunization, postnatal check or outpatient clinics (OPD) and had consented to participate in the study.

\section{Data Management}

The questionnaire was coded, pretested and included several skips with closed-ended questions to ensure consistency. At the end of each session, a supervisor reviewed each filled questionnaire to ensure completeness and accuracy before the participant would leave the facility after their visit. All the filled questionnaires were in the custody of the principal investigator (PI) of this study. At the end of each week, the collected data were entered into EpiData version 3.1 by two different people under the supervision of the PI.

\section{Data Analysis}

The data were exported to STATA Version 14 for cleaning, coding and analysis by the PI. All the continuous variables were summarised as means with the corresponding standard deviations (SD), while the categorical variables were summarised as frequencies and percentages. The outcome variable was categorized as use and non-use of any method of contraception based on the participants report. We used the Chi square test to determine the association between the primary outcome and various social demographic and economic factors at bivariable analysis. All factors with a P-value of at least $25 \%^{18}$ or a known risk factor from the literature were entered into a stepwise multivariable logistic regression model to determine the factors associated with contraceptive use in the final adjusted model. Multicollinearity between explanatory variables was assessed using the variance inflation factor (VIFs), and they were all less than 1.5. We reported the odds ratios and the corresponding 95\% confidence intervals as the measures of association. Confounding was considered present, if the difference between the crude and adjusted OR was $>10 \%$

\section{Ethical Considerations}

This study was approved by the Cure Children's hospital Research Ethics Committee (CCHU-REC/17/019). Administrative clearance to conduct the study was sought from the Town clerk of Mbale City and the respective facility heads. A written Informed consent was obtained from each of the respondents before enrollment into the study. Respondents below the legal age of 18 years in Uganda were treated as emancipated minors who can give a valid informed consent as per the guidelines of the Uganda National Council for Science and Technology. ${ }^{19}$ To ensure confidentiality, all the participant personal identifiers were eliminated from the questionnaires to anonymize them and each was assigned a unique identification code. All the filled questionnaires were kept under lock and key in the custody of the study PI. All the participants approached to participate in this study received extra education and counselling about contraception and all those that chose a method, received one at no extra cost. This study was conducted in accordance with the Declaration of Helsinki.

\section{Results}

\section{Baseline Characteristics}

Among the 511 teenage post-partum mothers interviewed, $323(63.2 \%)$ were married/cohabiting, 52.4\% (268) were bamasaba and 296 (57.9\%) attended post-primary education. Details are in Table 1. 
Table I Baseline Sociodemographic Characteristics of the Study Participants from Six Health Facilities in Mbale City

\begin{tabular}{|c|c|c|}
\hline \multirow[t]{2}{*}{ Characteristics } & \multicolumn{2}{|c|}{ Contraceptives n (\%) } \\
\hline & $\begin{array}{l}\text { Users } \\
(n=3 \mid 4)\end{array}$ & $\begin{array}{l}\text { None Users } \\
(n=197)\end{array}$ \\
\hline Mean age, years & $17.8(1.2)$ & $17.5(1.4)$ \\
\hline \multicolumn{3}{|l|}{ Marital status } \\
\hline Not married & $109(34.7)$ & $79(40)$ \\
\hline Married & $205(65.3)$ & $118(60)$ \\
\hline \multicolumn{3}{|l|}{ Religion } \\
\hline Anglican & $126(40.1)$ & $8 I(4 I . I)$ \\
\hline Moslem & $87(27.2)$ & $68(34.5)$ \\
\hline Catholic & $101(32)$ & $48(24)$ \\
\hline \multicolumn{3}{|l|}{ Tribe } \\
\hline Baganda & $54(17)$ & $38(19)$ \\
\hline Bamasaba & $169(54)$ & $99(50)$ \\
\hline Karimojong & $22(7)$ & $12(6)$ \\
\hline Itesot & $47(15)$ & $29(15)$ \\
\hline Others & $22(7)$ & $19(10)$ \\
\hline \multicolumn{3}{|l|}{ Employment status } \\
\hline Employed & III (35) & $72(37)$ \\
\hline Not Employed & $203(65)$ & $125(63)$ \\
\hline \multicolumn{3}{|l|}{ Level of education } \\
\hline Primary & $134(43)$ & $8 I(4 I)$ \\
\hline Post primary & $180(57)$ & $116(59)$ \\
\hline \multicolumn{3}{|l|}{ Division of residence } \\
\hline Northern & $75(24)$ & $56(28)$ \\
\hline Industrial & $146(46)$ & $104(53)$ \\
\hline Wanale & $93(30)$ & $37(19)$ \\
\hline \multicolumn{3}{|l|}{ Intention to resume school } \\
\hline Yes & II 5 (37) & $97(49)$ \\
\hline No & $|4|(45)$ & $65(33)$ \\
\hline Missing data & $58(18)$ & $35(18)$ \\
\hline \multicolumn{3}{|l|}{ ANC attendance } \\
\hline Yes & $303(96)$ & $183(93)$ \\
\hline No & II (4) & $14(7)$ \\
\hline \multicolumn{3}{|l|}{ Partner escort at ANC } \\
\hline Yes & $133(42)$ & $65(33)$ \\
\hline No & $|8|(58)$ & $132(67)$ \\
\hline \multicolumn{3}{|l|}{ Decision to get pregnant } \\
\hline Woman alone & $102(32)$ & $49(25)$ \\
\hline Man alone & $17(5)$ & $2 I(I I)$ \\
\hline Both & $195(62)$ & $127(64)$ \\
\hline \multicolumn{3}{|l|}{ Postnatal care attendance } \\
\hline Yes & $260(83)$ & $124(63)$ \\
\hline No & $54(17)$ & $73(37)$ \\
\hline
\end{tabular}

(Continued)
Table I (Continued).

\begin{tabular}{|l|l|l|}
\hline \multirow{2}{*}{ Characteristics } & \multicolumn{2}{|c|}{ Contraceptives n (\%) } \\
\cline { 2 - 3 } & $\begin{array}{l}\text { Users } \\
(\mathbf{n}=3 \text { I } 4)\end{array}$ & $\begin{array}{l}\text { None Users } \\
(\mathbf{n}=197)\end{array}$ \\
\hline $\begin{array}{l}\text { Mode of child birth } \\
\text { Vaginal birth } \\
\text { Caesarean section }\end{array}$ & $\begin{array}{l}282(90) \\
32(10)\end{array}$ & $\begin{array}{l}167(85) \\
30(15)\end{array}$ \\
\hline $\begin{array}{l}\text { Any complication in child } \\
\text { birth } \\
\text { Yes }\end{array}$ & $40(13)$ & $38(19)$ \\
No & $274(87)$ & $159(81)$ \\
\hline $\begin{array}{l}\text { Coupled discussed } \\
\text { contraception } \\
\text { Yes }\end{array}$ & $185(60)$ & $60(30)$ \\
No & $129(40)$ & $137(70)$ \\
\hline $\begin{array}{l}\text { Contraceptive use } \\
\text { sensitization by VHTs } \\
\text { Yes } \\
\text { No }\end{array}$ & $130(41)$ & $69(35)$ \\
\hline $\begin{array}{l}\text { Birth to birth interval } \\
<2 \text { years } \\
\geq 2 \text { years }\end{array}$ & $184(59)$ & $128(65)$ \\
\hline
\end{tabular}

Abbreviations: VHT, village health team; ANC, antenatal care.

\section{Prevalence of Contraceptive Use in the Postpartum Period}

Of the 511 individuals, $314(61.5 \%, 95 \% \mathrm{CI}=57.1-65.6 \%)$ had used or were using a method of contraception in the post-partum period. Of these, majority 202/314 (64.3\%) used injection, 14/314 (4.5\%) used intrauterine device, and the rest used an implant. Details are in Figure 1.

\section{Factors Associated with Postpartum Contraceptive Use Among Teenagers}

In the adjusted multivariable analysis, these factors were significantly associated with postpartum contraceptive use among teenagers in Mbale City: Intention to resume school (AOR 2.28, 95\% CI=1.44-3.62), utilization of postnatal care services (AOR 1.63, 95\% CI=1.25-2.12), when the decision to get pregnant was made by the woman alone (AOR 2.59, 95\% CI=1.52-4.41), and if the couple discussed contraception (AOR 4.12, 95\% CI=2.46-6.92). The details are in Table 2. Other variables were not significant. 


\section{Modern contraceptives used by teenage postpartum mothers in Mbale City}

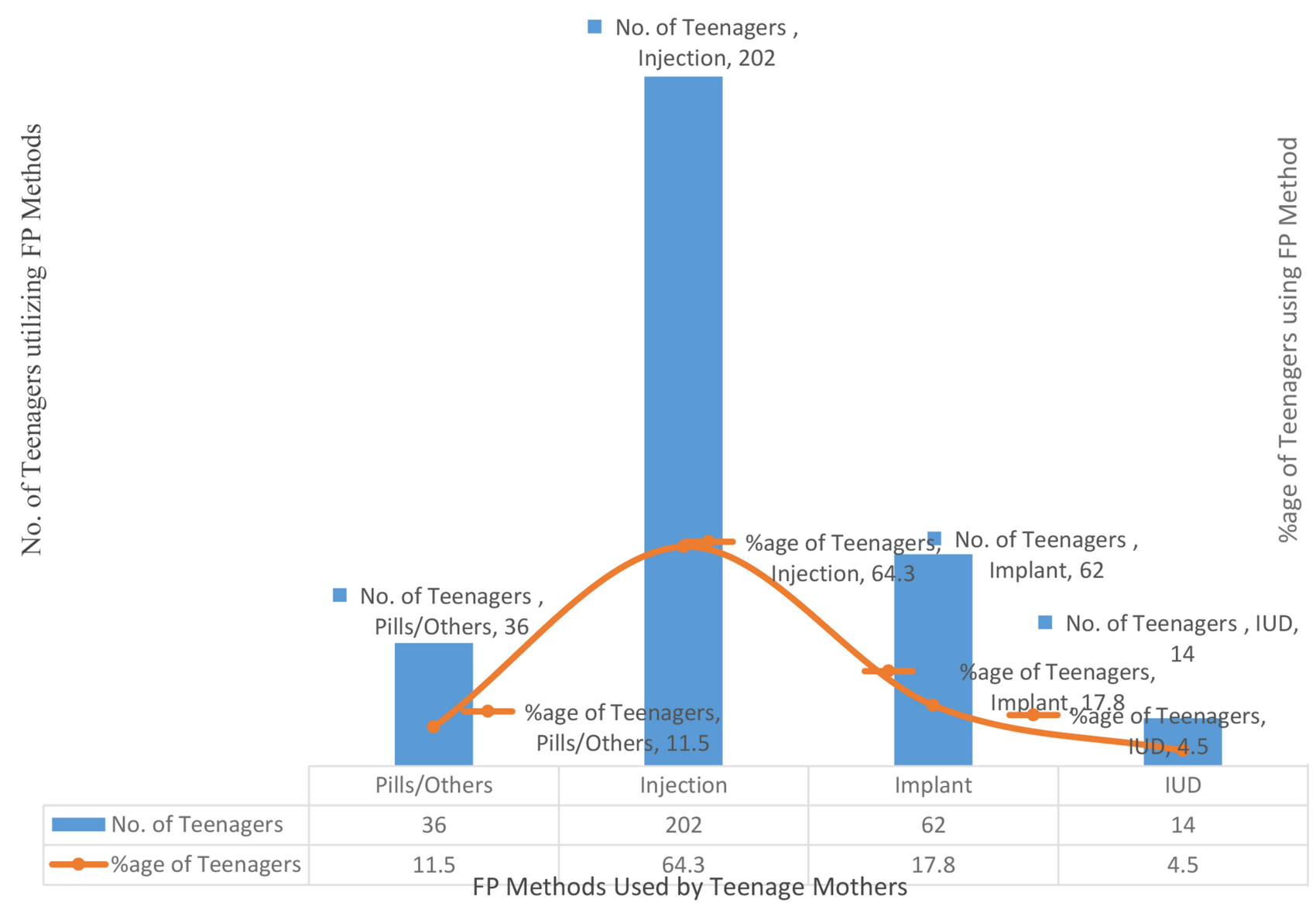

Figure I Different family planning methods used by postpartum teenage mothers in Mbale City.

\section{Discussion}

We investigated the prevalence and predictors of postpartum contraceptive use among teenage mothers in an urban setting in Eastern Uganda, Mbale City, using a crosssectional study that provided self-reported information of use in the first year postpartum period. We found a use prevalence higher than reported in other studies and it was associated with intention to resume school, postnatal care attendance, and involvement of the partner in reproductive health decisions. Below we discuss this in more detail.

The prevalence in postpartum modern contraceptive use was higher than what was reported at population level in Uganda. Using the data from the Uganda Demographic and Health of 2011, postpartum family planning use among women 15-19 years was found to be $24.1 \%{ }^{11}$ compared to our finding of over $60 \%$ use. This suggests that there are variations in use among adolescents; by rural-urban residence, access to information and services among others. This finding of a low prevalence was also found in other sub-Sahara Africa countries such as Malawi. ${ }^{20}$ The study in Malawi involved participants from rural setting who have limited access to contraceptive information and services. Generally, there is low uptake of modern postpartum contraceptives in sub-Sahara Africa. ${ }^{13}$ Use of contraceptives is affected by access to information and the health facilities in our study area. ${ }^{11}$

Second, we found that the women were using the shortterm methods; injectables were the most common method. This finding further aligns with previous research and survey findings that adolescent women prefer short-term methods. Majority of the women in Uganda use injection as their choice of contraceptive. ${ }^{21}$ Relatedly, a study by Kabagenyi et al found injectable to be the most preferred contraceptive method used by adolescents. ${ }^{12}$ This therefore calls for renewed efforts to promote long-term methods among this age category of women, who are also the 
Table 2 Factors Associated with Use of Postpartum Contraceptive Methods Among Teenage Mothers in Mbale City

\begin{tabular}{|c|c|c|c|c|}
\hline \multirow[t]{2}{*}{ Characteristics } & \multicolumn{2}{|c|}{ Contraceptives n (\%) } & \multirow{2}{*}{$\begin{array}{l}\text { Crude OR } \\
(95 \% \mathrm{CI})\end{array}$} & \multirow{2}{*}{$\begin{array}{l}\text { Adjusted OR } \\
(95 \% \mathrm{Cl})\end{array}$} \\
\hline & Users $(n=3 \mid 4)$ & None Users $(n=197)$ & & \\
\hline Mean age, years & I7.8 (I.2) & I7.5 (I.4) & $1.19(1.04-1.37)$ & \\
\hline \multicolumn{5}{|l|}{ Marital status } \\
\hline Not married & $109(34.7)$ & $79(40)$ & I & 1 \\
\hline Married & $205(65.3)$ & $118(60)$ & I.26 (0.87-I.82) & $1.16(0.76-1.77)$ \\
\hline \multicolumn{5}{|l|}{ Religion } \\
\hline Anglican & $126(40.1)$ & $81(4 I .1)$ & $0.74(0.47-1.15)$ & $0.7 \mathrm{I}(0.4 \mathrm{I}-1.0 \mathrm{I})$ \\
\hline Moslem & $87(27.2)$ & $68(34.5)$ & $0.6 \mathrm{I}(0.38-0.97)$ & $0.65(0.43-1.00)$ \\
\hline Catholic & $101(32)$ & $48(24)$ & 1 & 1 \\
\hline \multicolumn{5}{|l|}{ Tribe } \\
\hline Baganda & $54(17)$ & $38(19)$ & I & \\
\hline Bamasaba & $169(54)$ & $99(50)$ & $1.20(0.74-1.95)$ & - \\
\hline Karimojong & $22(7)$ & $12(6)$ & $1.29(0.57-2.92)$ & - \\
\hline Itesot & $47(15)$ & $29(15)$ & $1.14(0.6 \mathrm{I}-2.12)$ & - \\
\hline Others & $22(7)$ & $19(10)$ & $0.8 \mathrm{I}(0.39-1.7 \mathrm{I})$ & - \\
\hline \multicolumn{5}{|c|}{ Employment status } \\
\hline Employed & III (35) & $72(37)$ & 1 & \\
\hline Not Employed & $203(65)$ & $125(63)$ & $1.05(0.73-1.53)$ & - \\
\hline \multicolumn{5}{|c|}{ Level of education } \\
\hline Primary & $134(43)$ & $8 I(4 I)$ & 1 & \\
\hline Post primary & $180(57)$ & $116(59)$ & $0.94(0.65-1.35)$ & - \\
\hline \multicolumn{5}{|c|}{ Division of residence } \\
\hline Northern & $75(24)$ & $56(28)$ & 1 & 1 \\
\hline Industrial & $146(46)$ & $104(53)$ & $\mathrm{I} .05(0.68-1.6 \mathrm{I})$ & $1.02(0.63-1.68)$ \\
\hline Wanale & $93(30)$ & $37(19)$ & $1.88(1.12-3.14)$ & $1.79(0.97-3.28)$ \\
\hline \multicolumn{5}{|c|}{ Intention to resume school* } \\
\hline Yes & $115(37)$ & $97(49)$ & $1.82(1.23-2.73)$ & $2.28(1.44-3.62)$ \\
\hline No & $|4|(45)$ & $65(33)$ & 1 & 1 \\
\hline Missing data & $58(18)$ & $35(18)$ & - & - \\
\hline \multicolumn{5}{|l|}{ ANC attendance } \\
\hline Yes & $303(96)$ & $183(93)$ & 1 & 1 \\
\hline No & II (4) & $14(7)$ & $0.47(0.21-1.07)$ & $0.8 I(0.3 I-2.1 I)$ \\
\hline \multicolumn{5}{|c|}{ Partner escort at ANC } \\
\hline Yes & $133(42)$ & $65(33)$ & 1 & 1 \\
\hline No & $|8|(58)$ & $132(67)$ & $0.67(0.46-0.97)$ & $1.03(0.67-1.59)$ \\
\hline \multicolumn{5}{|c|}{ Decision to get pregnant* } \\
\hline Both & $195(62)$ & $127(64)$ & 1 & 1 \\
\hline Woman alone & $102(32)$ & $49(25)$ & $1.36(0.90-2.04)$ & $2.59(I .52-4.4 I)$ \\
\hline Man alone & $17(5)$ & $2 I(I I)$ & $0.53(0.27-1.04)$ & $0.99(0.42-2.30)$ \\
\hline \multicolumn{5}{|c|}{ Postnatal care attendance* } \\
\hline No & $54(17)$ & $73(37)$ & I & I \\
\hline Yes & $260(83)$ & $124(63)$ & $1.68(1.37-2.07)$ & $1.63(1.25-2.12)$ \\
\hline
\end{tabular}

(Continued) 
Table 2 (Continued).

\begin{tabular}{|c|c|c|c|c|}
\hline \multirow[t]{2}{*}{ Characteristics } & \multicolumn{2}{|c|}{ Contraceptives n (\%) } & \multirow{2}{*}{$\begin{array}{l}\text { Crude OR } \\
(95 \% \mathrm{Cl})\end{array}$} & \multirow{2}{*}{$\begin{array}{l}\text { Adjusted OR } \\
(95 \% \mathrm{Cl})\end{array}$} \\
\hline & Users $(n=3 \mid 4)$ & None Users $(n=197)$ & & \\
\hline \multicolumn{5}{|l|}{ Mode of child birth } \\
\hline Vaginal birth & $282(90)$ & $167(85)$ & 1 & 1 \\
\hline Caesarean section & $32(10)$ & $30(15)$ & $1.69(0.37-1.08)$ & $0.67(0.35-1.32)$ \\
\hline \multicolumn{5}{|c|}{ Any complication in child birth } \\
\hline Yes & $40(13)$ & $38(19)$ & I & 1 \\
\hline No & $274(87)$ & $159(81)$ & $1.64(1.01-2.66)$ & $1.70(0.93-3.12)$ \\
\hline \multicolumn{5}{|c|}{ Coupled discussed contraception* } \\
\hline No & $129(40)$ & $137(70)$ & I & 1 \\
\hline Yes & $185(60)$ & $60(30)$ & $3.27(2.24-4.78)$ & $4.12(2.46-6.92)$ \\
\hline \multicolumn{5}{|l|}{ Sensitised by VHTs } \\
\hline Yes & $130(4 \mid)$ & $69(35)$ & 1 & 1 \\
\hline No & $184(59)$ & $128(65)$ & $0.76(0.53-1.10)$ & $\mathrm{I} .34(0.87-2.0 \mathrm{I})$ \\
\hline \multicolumn{5}{|l|}{ Birth to birth interval } \\
\hline$<2$ years & $46(15)$ & $28(14)$ & I & - \\
\hline$\geq 2$ years & $268(85)$ & $169(86)$ & $0.97(0.58-1.60)$ & \\
\hline
\end{tabular}

Note: *Significant with P-value $<0.05$.

Abbreviation: UOR, unadjusted odds ratio; AOR, adjusted odds ratio.

most vulnerable to forgetting to use the method. Use of the most effective methods like IUD and Implants remained low for adolescent women by 6 months post pregnancy. ${ }^{22}$

Third, we found that adolescent women who had intention to pursue schooling took up contraception, including those who attended PNC. These results affirm previous research findings that PNC attendance is an important point for receiving postpartum contraceptives. ${ }^{23}$ Further, adolescent women who have alternative opportunities are more likely to make conscious decisions to prevent a repeat pregnancy so as to pursue their goal. ${ }^{24}$ This calls for a renewed effort to avail adolescent girls' opportunities to continue with schooling and take up contraceptives.

Lastly, we found that women whose decision to get pregnant was made by the partner or had had a discussion with the partner on contraceptive use, were not likely to use contraceptives. This suggests the role of patriarchy and partner coercion in contraception use. Previous research findings have documented that male partners object to women using contraceptives. ${ }^{25,26}$ This control is worse for the adolescent women who are more vulnerable to coercion. These findings call for renewed focus on empowering adolescent women to take charge of their fertility intentions. Contraception needs to be offered in a manner that promotes autonomy of the adolescent woman; with limited partner interference.

\section{Strengths and Limitations of the Study}

Our study was adequately powered to study the association between use of contraceptives and various sociodemographic characteristics. Some of the limitations include the nature of the study design and self-reported information. This could have introduced reporting bias as respondents may opt to give socially desirable responses and others may have had a challenge with recalling information due to time-lapse. Some teenage girls in their postpartum period of up to 1 year declined to participate satisfactorily in the study due to reasons like; being busy with work, others were in a hurry to do housework, or shy away thinking the study is judgmental.

\section{Conclusion}

In this urban adolescent population, we found a high prevalence of postpartum contraceptive use- over 6 in 10 women-although they were using mainly short-term methods. Adolescent women with intentions of resuming schooling and those who attended PNC were most likely to use contraceptives. This is encouraging and calls for inquiry into why their use is higher than the national averages. Further, 
the results call for renewed efforts to maintain adolescent mothers in school. Lastly, efforts should reduce partner coercion by empowering the women.

\section{Acknowledgments}

We want to thank the respondents for this study as well as the research assistants.

\section{Disclosure}

The authors report no conflicts of interest in this work.

\section{References}

1. Abraha TH, Gebrezgiabher BB, Aregawi BG, Belay DS, Tikue LT, Welay GM. Predictors of postpartum contraceptive use in rural Tigray region, northern Ethiopia: a multilevel analysis. BMC Public Health. 2018;18(1):1-10.

2. Asiimwe JB, Ndugga P, Mushomi J, Menyenye Ntozi JP. Factors associated with modern contraceptive use among young and older women in Uganda; a comparative analysis. BMC Public Health. 2014;8(14):926. doi:10.1186/1471-2458-14-926

3. Balkus J, Bosire R, John-Stewart G, et al. High uptake of postpartum hormonal contraception among HIV-1-seropositive women in Kenya. Sex Transm Dis. 2007;34(1):25-29. doi:10.1097/01.olq.000021 8880.88179 .36

4. Brunson MR, Klein DA, Olsen CH, Weir LF, Roberts TA. Postpartum contraception: initiation and effectiveness in a large universal healthcare system. Am J Obstet Gynecol. 2017;217(1):55.e155.e9. doi:10.1016/j.ajog.2017.02.036

5. Charles JM, Rycroft-Malone J, Aslam R, Hendry M, Pasterfield D, Whitaker R. Reducing repeat pregnancies in adolescence: applying realist principles as part of a mixed-methods systematic review to explore what works, for whom, how and under what circumstances. BMC Pregnancy Childbirth. 2016;16(1):271. doi:10.1186/s12884016-1066-x

6. Cleland J, Bernstein S, Ezeh A, Faundes A, Glasier A, Innis J. Family planning: the unfinished agenda. Reprod Health Ser. 2006.

7. Conroy KN, Engelhart TG, Martins Y, et al. The enigma of rapid repeat pregnancy: a qualitative study of teen mothers. $J$ Pediatr Adolesc Gynecol. 2016;29(3):312-317. doi:10.1016/j. jpag.2015.12.003

8. Dasgupta ANZ, Zaba B, Crampin AC. Postpartum uptake of contraception in rural northern Malawi: a prospective study. Contraception. 2016;94(5):499-504. doi:10.1016/j.contraception.2016.05.007

9. Dee DL, Pazol K, Cox S, et al. Trends in repeat births and use of postpartum contraception among teens - United States, 2004-2015. MMWR Morb Mortal Wkly Rep. 2017;66(16):422-426.

10. Dona A, Abera M, Alemu T, Hawaria D. Timely initiation of postpartum contraceptive utilization and associated factors among women of child bearing age in Aroressa District, Southern Ethiopia: a community based cross-sectional study. BMC Public Health. 2018;18(1):1-9. doi:10.1186/s12889-018-5981-9

11. Rutaremwa G, Kabagenyi A, Wandera SO, Jhamba T, Akiror E, Nviiri HL. Predictors of modern contraceptive use during the postpartum period among women in Uganda: a population-based cross sectional study. BMC Public Health. 2015;15(1):262. doi:10.1186/ s12889-015-1611-y
12. Kabagenyi A, Habaasa G, Rutaremwa G. Low contraceptive use among young females in uganda: does birth history and age at birth have an influence? Analysis of 2011 demographic and health survey. $J$ Contracept Stud. 2016;1(1):1-12.:

13. Eliason S, Baiden F, Quansah-Asare G, et al. Factors influencing the intention of women in rural Ghana to adopt postpartum family planning. Reprod Health. 2013;10(1):34. doi:10.1186/1742-4755-10-34

14. Fuell Wysong E, Tossone K, Furman L. Expectant inner-city women: attitudes about contraception given infant feeding choice. Eur $J$ Contracept Reprod Health Care. 2017;22(5):369-374. doi:10.1080/13625187.2017.1397110.

15. Musaba MW, Ndeezi G, Barageine JK, et al. Risk factors for obstructed labour in Eastern Uganda: a case control study. PLoS One. 2020;15(2):e0228856-e0228856. doi:10.1371/journal.pone.0 228856

16. Sullivan KM, Soe MM. Sample size for a cross-sectional, cohort, or clinical trial studies sample size for cross-sectional \& cohort studies \& clinical trials; 2007 [cited November 8, 2017]. Available from: http://www.openepi.com/PDFDocs/SSCohortDoc.pdf. Accessed December 3, 2020.

17. Hounton S, Winfrey W, Barros AJD, Askew I. Patterns and trends of postpartum family planning in Ethiopia, Malawi, and Nigeria: evidence of missed opportunities for integration. Glob Health Action. 2015;8(1):29738. doi:10.3402/gha.v8.29738

18. Hosmer DW, Lemeshow S, Sturdivant RX, et al. Applied Logistic Regression. Cressie NAC, Fisher NI, Johnstone IM, Kadane JB, Scott D, Silverman BW, editors. New York:John Wiley \& Sons, INC; 2000:31-43.

19. Uganda National Council for Science and Technology. National Guidelines for Research Involving Humans as Research Participants. Kampala, Uganda;2007:1-60.

20. Kopp DM, Rosenberg NE, Stuart GS, et al. Patterns of contraceptive adoption, continuation, and switching after delivery among Malawian women. PLoS One. Leone T, editor. 2017;12(1):e170284. doi:10.1371/journal.pone. 0170284

21. Government of Uganda. Uganda demographic and health survey 2016 key indicators report. government of uganda. uganda demographic and health survey 2016 key indicators report [Internet]. Kampala, Uganda; 2017. Available from: http://www.ubos.org/online files/uploads/ubos/pdfdocuments/Uganda_DHS_2016_KIR.pdf.

22. Rominski SD, Sk Morhe E, Maya E, Manu A, Dalton VK. Comparing women's contraceptive preferences with their choices in 5 urban family planning clinics in Ghana. Glob Health Sci Pract. 2017;5(1):65-74. doi:10.9745/GHSP-D-16-00281.

23. Teka TT, Feyissa TR, Melka AS, Bobo FT. Role of antenatal and postnatal care in contraceptive use during postpartum period in western Ethiopia: a cross sectional study. BMC Res Notes. 2018;11 (1):581. doi:10.1186/s13104-018-3698-6

24. Masemola-Yende JPF, Mataboge SM. Access to information and decision making on teenage pregnancy prevention by females in Tshwane. Curationis. 2015;38(2):1540.

25. Truong S, Villar de Onis J, Lindley A, et al. Gender-informed family planning perceptions and decision-making in rural Chiapas, Mexico: a mixed-methods study. Int $J$ Reprod Med. Agca Y, editor. 2020;2020:1929143. doi:10.1155/2020/1929143

26. Ezeanolue EE, Iwelunmor J, Asaolu I, et al. Impact of male partner's awareness and support for contraceptives on female intent to use contraceptives in southeast Nigeria. BMC Public Health. 2015;15 (1):879. doi:10.1186/s12889-015-2216-1 


\section{Publish your work in this journal}

Open Access Journal of Contraception is an international, peerreviewed, open access, online journal, publishing original research, reports, reviews and commentaries on all areas of contraception. In addition to clinical research, demographics and health-related aspects, the journal welcomes new findings in animal and preclinica studies relating to understanding the biological mechanisms and practical development of new contraceptive agents. The manuscript management system is completely online and includes a very quick and fair peer-review system. Visit http://www.dovepress.com/testimonials. php to read real quotes from published authors. 